Article

\title{
Synthesis of FePcS-PMA-LDH Cointercalation Composite with Enhanced Visible Light Photo-Fenton Catalytic Activity for BPA Degradation at Circumneutral pH
}

\author{
Fenglian Huang ${ }^{1}$, Shiqiang Tian ${ }^{1}$, Yan $\mathrm{Qi}^{1}{ }^{1}$, Erping $\mathrm{Li}^{1}$, Liangliang Zhou ${ }^{1}$ and Yaqun Qiu ${ }^{1,2, *}$ \\ 1 Hunan Provincial Key Laboratory of Water Pollution Control Technology, Hunan Academy of Environmental \\ Protection Sciences, Changsha 410004, Hunan, China; 2hfl@163.com (F.H.); hnhkytsq@sina.com (S.T.); \\ qiyan887@126.com (Y.Q.); lvtu1214@sina.com (E.L.); zhousunset@foxmail.com (L.Z.) \\ 2 College of Environmental Science and Engineering, Central South University of Forestry and Technology, \\ Changsha 410004, Hunan, China \\ * Correspondence: qiuyaqun9186@163.com
}

Received: 14 February 2020; Accepted: 3 April 2020; Published: 21 April 2020

check for updates

\begin{abstract}
Background: Iron tetrasulfophthalocyanine with a large nonlinear optical coefficient, good stability, and high catalytic activity has aroused the attention of researchers in the field of photo-Fenton reaction. Further improvement of the visible light photo-Fenton catalytic activity under circumneutral $\mathrm{pH}$ conditions for their practical application is still of great importance. (2) Methods: In this paper, iron tetrasulfophthalocyanine (FePcS) and phosphomolybdic acid (PMA) cointercalated layered double hydroxides (LDH) were synthesized by the ion-exchange method. All samples were fully characterized by various techniques and the results showed that FePcS and PMA were successfully intercalated in layered double hydroxides and the resulted compound exhibited strong absorption in the visible light region. The cointercalation compound was tested as a heterogeneous catalyst for the visible light photo-Fenton degradation of bisphenol A (BPA) at circumneutral $\mathrm{pH}$. (3) Results: The results showed that the degradation and total organic carbon removal efficiencies of bisphenol A were $100 \%$ and $69.2 \%$, respectively. (4) Conclusions: The cyclic voltammetry and electrochemical impedance spectroscopy measurements demonstrated that the main contribution of PMA to the enhanced photo-Fenton activity of FePcS-PMA-LDH comes from the acceleration of electron transfer in the reaction system. Additionally, the possible reaction mechanism in the photo-Fenton system catalyzed by FePcS-PMA-LDH was also proposed.
\end{abstract}

Keywords: photo-Fenton; iuron tetrasulfophthalocyanine; phosphomolybdic acid; layered double hydroxides; circumneutral $\mathrm{pH}$

\section{Introduction}

In recent years, great endeavors have been made to develop efficient chelating agents for stabilizing iron and enhancing the photo-Fenton degradation of refractory organic contaminants in water under neutral $\mathrm{pH}$ conditions [1-4]. To date, a large number of Fe complexes such as Fe-ethylenediaminetetraacetic acid, Fe-oxalate, Fe-ethylenediamine- $N$, $N^{\prime}$-disuccinic acid, and iron phthalocyanine complex (FePc) have been reported as photo-Fenton catalysts [5-8], in which FePc has been found to have good response to visible light $[7,9-11]$. Under visible light irradiation, effective energy transfer can occur between the excited $\mathrm{FePc}$ and $\mathrm{H}_{2} \mathrm{O}_{2}$, resulting in the formation of the $\bullet \mathrm{OH}$ radical, which can oxidize organic matter with high efficiency [12]. However, the practical application of FePc is limited because of the low quantum yield of $\bullet \mathrm{OH}$ resulting from the short life of excited MPc [13]. 
Coupling FePc with polyoxometalates (POM) may be an effective strategy to improve the utilization of electronically excited FePc. Previous studies have shown that POM can act as an electron acceptor and lead to the formation of reduced POM [14-18], which can not only accelerate the transfer of $\mathrm{Fe}(\mathrm{III})$ to $\mathrm{Fe}(\mathrm{II})$ in $\mathrm{FePc}$, but can also activate hydrogen peroxide or oxygen to produce various reactive oxygen species with strong oxidizing property [19]. Inspired by these studies, we expect that the introduction of phosphomolybdic acid (PMA), a Keggin polyoxometalate, can greatly enhance the photo-Fenton catalytic activity of FePc. Considering the high solubility of FePcS and PMA in aqueous media, the immobilization of FePcS-PMA is of great importance for the recovery and reuse of this catalyst. Layered double hydroxides (LDHs) have been considered as attractive materials for their high surface area, variable gallery height, and strong adsorption performance [20-22]. Moreover, due to the remarkable anion-exchange capacity, LDHs are very suitable supporters for the immobilization of the anionic complex [23,24].

With this understanding, we report herein the synthesis of FePcS-PMA-LDH composite catalyst using ZnAl-layered double hydroxide (ZnAl-LDH) as the host material to support FePcS and PMA. The as-prepared catalyst was used as an efficient heterogeneous catalyst for the photo-Fenton degradation of bisphenol A (BPA) under visible light irradiation and neutral $\mathrm{pH}$.

\section{Materials and Methods}

\subsection{Synthesis of FePcS-PMA-LDH}

$\mathrm{ZnAl}-\mathrm{LDH}$ with a $\mathrm{Zn} / \mathrm{Al}$ ratio of 2 was prepared through the co-precipitation method at a constant $\mathrm{pH}$ of 6. FePcS was synthesized and purified according to the method of Griffin [25]. To synthesize the FePcS-PMA-LDH, a $100 \mathrm{~mL}$ suspension containing $2.0 \mathrm{~g} \mathrm{ZnAl}-\mathrm{LDH}$ was added dropwise to a $50 \mathrm{~mL}$ mixed solution of FePcS/PMA (0.02 g:0.06 g) under magnetic stirring and an inert atmosphere. In addition, $20 \mathrm{~mL}$ of ethylene glycol and $20 \mathrm{~mL}$ of ethanol were added to the reacting mixture, which was sonicated for $10 \mathrm{~min}$ to obtain a homogeneous dispersion and was then magnetically stirred for $24 \mathrm{~h}$. The obtained precipitate was filtered and washed with deionized water under an inert atmosphere, and then dried at $60{ }^{\circ} \mathrm{C}$ under vacuum.

\subsection{Characterization}

The x-ray diffraction (XRD) patterns were investigated by a LabX-6000 diffractometer (Shimadzu, Hong Kong, China). The Fourier transform infrared (FTIR) spectra were recorded by a Nicolet 380 FTIR spectrometer using $\mathrm{KBr}$ pellets at room temperature. The zeta potential values were measured using a Zeta sizer (nano zs90, Malvern Instruments, Worcestershire, UK). The Brunauer-Emmett-Teller (BET) measurements of the materials were taken on a IGA 100B instrument (Hiden, Warrington, England). Diffuse reflectance-UV-Vis (DRS-UV-Vis) measurements were performed on a Shimadzu UV-2550 double-beam digital spectrometer (Hong Kong, China) equipped with conventional components of a reflectance spectrometer. Scanning electron microscopy (SEM) images were obtained using a scanning electron microscope (SEM, JSM-6360LV, JEOL, Peabody, MA, USA).

The electrochemical measurements were performed with a CHI660 Electrochemical Workstation (Shanghai Chenhua Instrumental Co. Ltd., Shanghai, China) and a conventional three-electrode system, in which a ZnAl-LDH/FePcS-LDH/FePcS-PMA-LDH modified glassy carbon electrode (GCE), a platinum plate, and a saturated calomel electrode were used as the working, counter, and reference electrodes, respectively. The electrolyte was $0.1 \mathrm{M} \mathrm{KCl}$ solution containing $5 \mathrm{mM}$ $\mathrm{K}_{3}\left[\mathrm{Fe}(\mathrm{CN})_{6}\right] / \mathrm{K}_{4}\left[\mathrm{Fe}(\mathrm{CN})_{6}\right](1: 1)$ mixture. Cyclic voltammetry $(\mathrm{CV})$ experiments were conducted at a sweep rate of $100 \mathrm{mV} / \mathrm{s}$ and the scan range was from -0.2 to $+0.8 \mathrm{~V}$. The electrochemical impedance spectra (EIS) were obtained over the frequency range from $100 \mathrm{kHz}$ to $0.01 \mathrm{~Hz}$ with an AC signal amplitude of $10 \mathrm{mV}$. 


\subsection{Photocatalytic Tests and Analytical Methods}

The photocatalytic experiments were conducted in a photochemical reaction instrument (BL-GHX-CH500, Xi'an Depai Biotech. Co. Ltd., Xi'an, China) and a $500 \mathrm{~W}$ xenon lamp was applied as the visible-light source. Typically, $40 \mathrm{mg}$ FePcS-PMA-LDH was added to $100 \mathrm{~mL}$ of BPA solution with the initial concentration of $10 \mathrm{mg} \mathrm{L}^{-1}$. The initial $\mathrm{pH}$ value of the solution was adjusted by adding $\mathrm{NaOH}$ or $\mathrm{HNO}_{3}$ solutions. The mixed solution was magnetically stirred for $30 \mathrm{~min}$ in the dark to achieve adsorption equilibrium between FePcS-PMA-LDH and BPA. Then, the xenon lamp was turned on and $\mathrm{H}_{2} \mathrm{O}_{2}$ was added to the BPA solution. At predetermined time intervals, the sample was taken out and centrifuged to obtain the supernatant for analysis. The concentration of the remaining BPA in the aqueous solution was determined with high efficiency liquid chromatography (HPLC, Agilent 1260). The concentration of Total Organic Carbon (TOC) during the degradation solutions was measured by a TOC analyzer (Shimadzu TOC-L CPH CN 200, Kyoto, Japan) equipped with an auto-sampler. Electron spin resonance (ESR) spectra of $\bullet \mathrm{OH}, \mathrm{O}_{2}{ }^{\bullet-}$, and ${ }^{1} \mathrm{O}_{2}$ were tested by an ESR spectrometer (JEOL JES-FA, Peabody, MA, USA).

\section{Results}

\subsection{Characterization of Catalyst}

Figure 1 shows the XRD patterns of ZnAl-LDH, FePcS-LDH, and FePcS-PMA-LDH. As demonstrated in the diffractograms of $\mathrm{ZnAl}-\mathrm{LDH}$, the diffraction peaks at $2 \theta=9.8^{\circ}(003), 19.8^{\circ}$ (006), 34.2 (009) matched well with the characteristic peaks of the reported ZnAl-LDH [26-28]. The above peaks can also be found in the patterns of FePcS-LDH and FePcS-PMA-LDH, but slightly shifted to lower angles when compared with ZnAl-LDH. Additionally, the value of the basal distance increased from $0.894 \mathrm{~nm}$ for ZnAl-LDH to $1.037 \mathrm{~nm}$ and $1.046 \mathrm{~nm}$ for FePcS-LDH and FePcS-PMA-LDH, respectively (Table 1). These results indicate the interlayer space of ZnAl-LDH is expanded after intercalated by FePcS and FePcS-PMA.

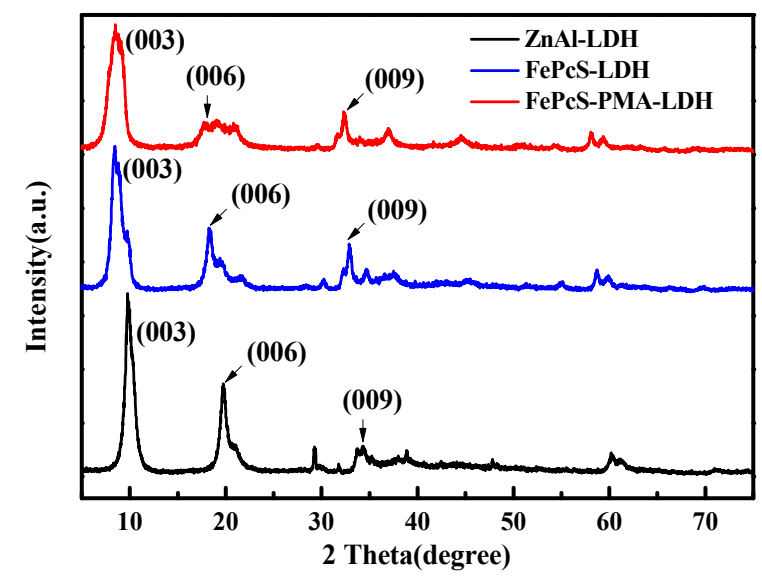

Figure 1. X-ray diffraction (XRD) patterns of ZnAl-LDH, FePcS-LDH, and FePcS-PMA-LDH.

Table 1. Basal spacing of ZnAl-LDH, FePcS-LDH, and FePcS-PMA-LDH, determined by the Bragg's Law.

\begin{tabular}{ccccc}
\hline \multirow{2}{*}{ Samples } & \multicolumn{2}{c}{$\left.\mathbf{(}^{\circ}\right)$} & Basal Spacing (nm) \\
\cline { 2 - 4 } & $\mathbf{( 0 0 3 )}$ & $\mathbf{( 0 0 6 )}$ & $\mathbf{( 0 0 9 )}$ & $\mathbf{( 0 0 3 )}$ \\
\hline ZnAl-LDH & 9.88 & 19.68 & 33.78 & 0.894 \\
\hline FePcS-LDH & 8.52 & 18.26 & 32.22 & 1.037 \\
\hline FePcS-PMA-LDH & 8.44 & 18.08 & 32.36 & 1.046 \\
\hline
\end{tabular}


The molecular structure and chemical nature of ZnAl-LDH, FePcS-LDH, and FePcS-PMA-LDH were analyzed by FTIR spectra, which are shown in Figure 2. In the spectrum of ZnAl-LDH, the characteristic absorption peaks at 3446,1630, and $1403 \mathrm{~cm}^{-1}$ can be attributed to the O-H stretching vibration of interlayer water molecules, the bending vibration of $\mathrm{H}_{2} \mathrm{O}$ in the brucite-like layer, and the stretching vibration of nitrate, respectively [29-31]. Compared to the ZnAl-LDH sample, the FTIR spectra of FePcS-LDH and FePcS-PMA-LDH appeared as a new absorption band at $1120 \mathrm{~cm}^{-1}$, which was assigned to the stretching vibration absorption of the $\mathrm{S}=\mathrm{O}$ bond in FePcS [32,33], whereas the infrared absorbance near $647 \mathrm{~cm}^{-1}$ was assigned to the vibration absorption of $\mathrm{C}-\mathrm{H}$ out-of-plane ring bend on the aromatic ring in FePcS [34]. Furthermore, in contrast to ZnAl-LDH, the FTIR spectrum of FePcS-PMA-LDH appeared as characteristic peaks of PMA. The absorption peak at $871 \mathrm{~cm}^{-1}$ corresponded to the stretching vibrations of $\mathrm{Mo}-\mathrm{O}_{\mathrm{c}}-\mathrm{Mo}$ and $\mathrm{Mo}-\mathrm{O}_{\mathrm{b}}-\mathrm{Mo}$ bands, and the stretching vibrations at $966 \mathrm{~cm}^{-1}$ and $1064 \mathrm{~cm}^{-1}$ referred to $\mathrm{Mo}=\mathrm{O}_{d}$ and $\mathrm{P}-\mathrm{O}_{\mathrm{a}}$ bands [35-37].The results of the FTIR spectra further confirmed the successful modification of FePcS and FePcS-PMA in ZnAl-LDH.

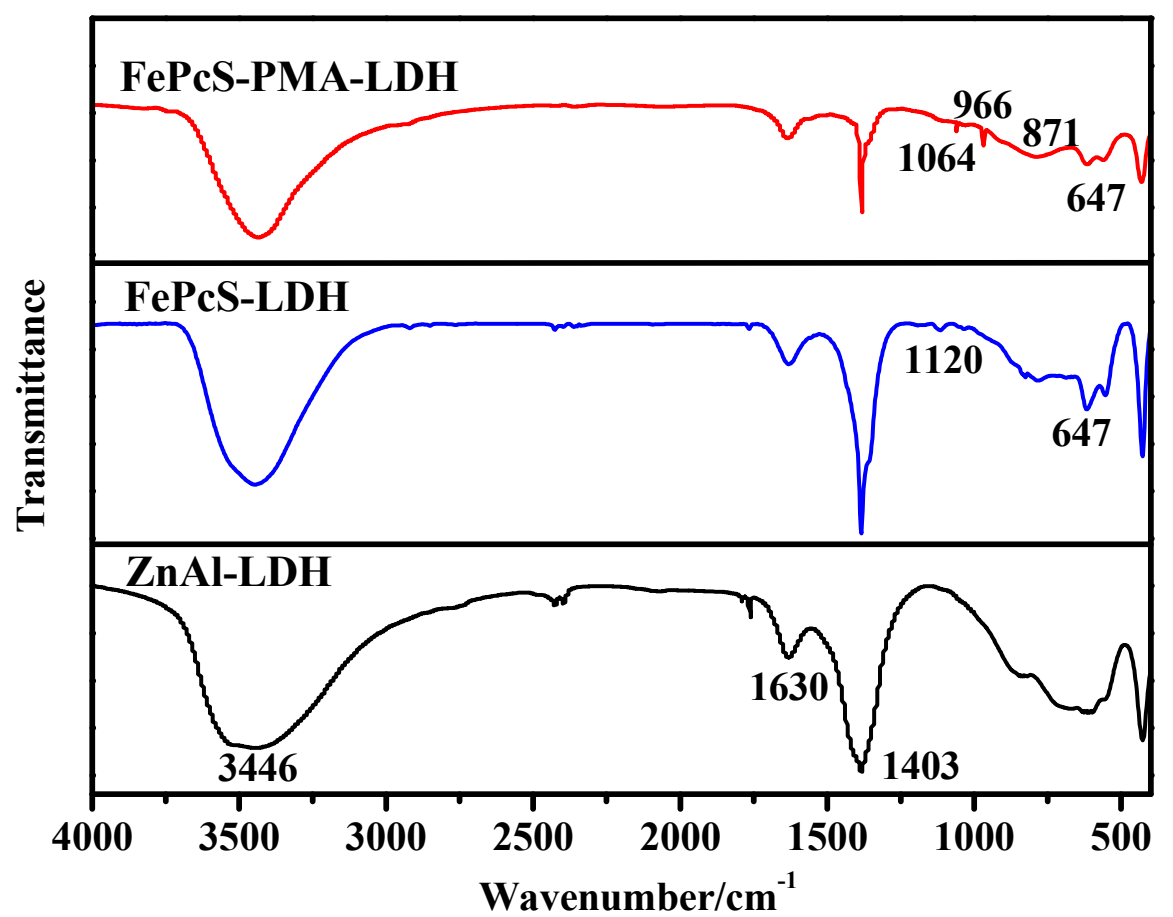

Figure 2. Fourier transform infrared (FTIR) spectra of ZnAl-LDH, FePcS-LDH, and FePcS-PMA-LDH.

Figure 3 presents the evolution of the zeta potential as a function of $\mathrm{pH}$ for the $\mathrm{ZnAl}-\mathrm{LDH}$, FePcS-LDH, and FePcS-PMA-LDH with the particle concentration of $2 \mathrm{~g} / \mathrm{L}$. As can be seen, the zeta potential values of $\mathrm{ZnAl}-\mathrm{LDH}$ were positive in a wide range of $\mathrm{pH}(\mathrm{pH}=4-10)$, which resulted from the structural charge and the hydroxyl groups located on the surface of the $\mathrm{ZnAl}-\mathrm{LDH}$ particles [38]. However, the zeta potential values for FePcS-LDH and FePcS-PMA-LDH were reversed to negative because of the immobilization of FePcS and FePcS-PMA. The physical electrostatic force between the LDH's structural positive charges and anionic charge compounds is one of the main interaction forces between LDHs and the anionic compounds [39]. Therefore, the immobilized anionic compounds can neutralize the structural charges of ZnAl-LDH. It should be noted that FePcS-PMA exhibited more negative zeta potential values than FePcS-LDH. This result also reflects that FePcS and PMA have been cointercalated into the interlayer galleries of ZnAl-LDH.

The surface morphologies of the catalysts were examined by SEM. As shown in Figure 4, the surface of ZnAl-LDH was smooth, while relatively rough surfaces of FePcS-LDH and FePcS-PMA-LDH particles can be observed, which may result from the homogeneous distributions of FePcS and FePcS-PMA on the LDHs surface. It also should be noted that FePcS-PMA-LDH exhibited a rougher 
surface morphology compared with FePcS-LDH, indicating that FePcS-PMA-LDH can provide more adsorption sites than FePcS-LDH.

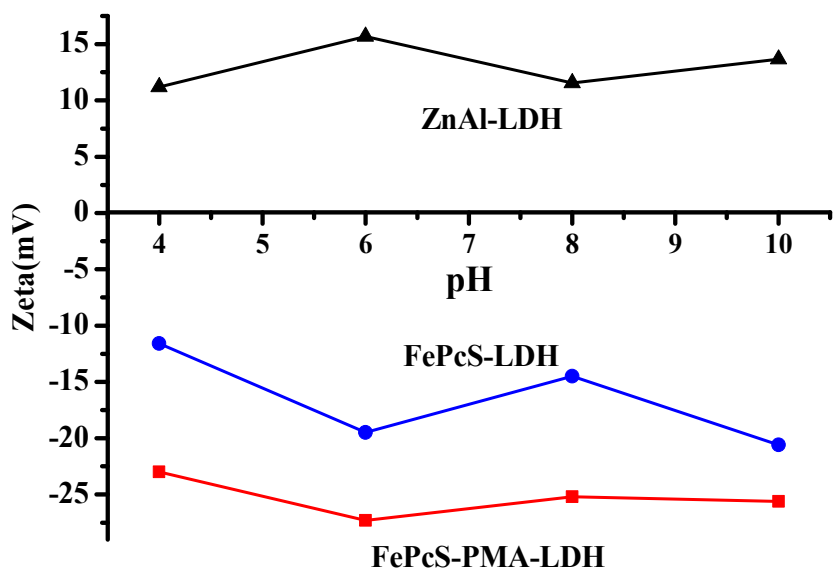

Figure 3. Variation of zeta potential with $\mathrm{pH}$ of ZnAl-LDH, FePcS-LDH, and FePcS-PMA-LDH.

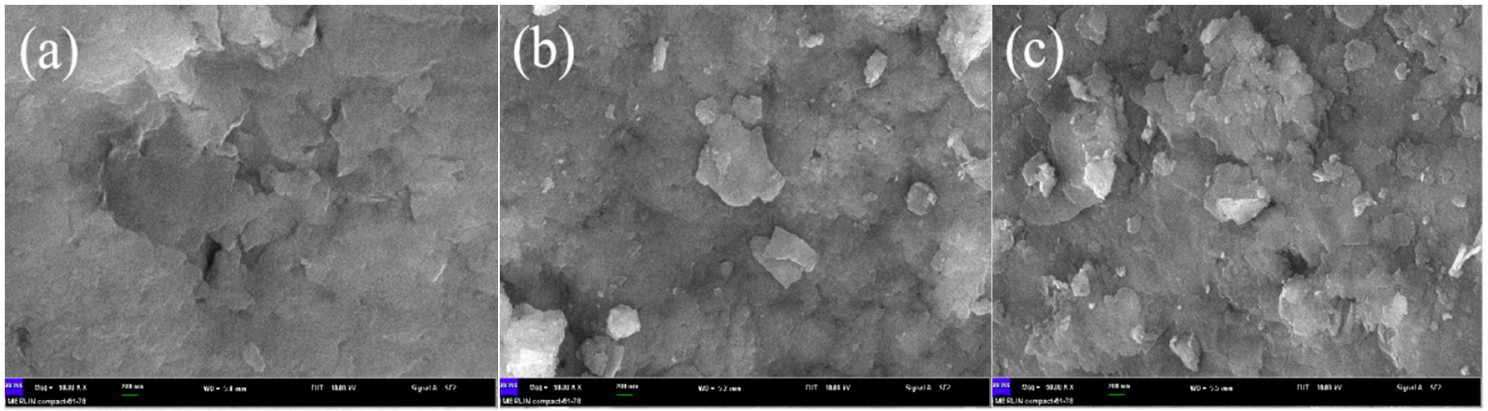

Figure 4. Scanning electron microscopy (SEM) images of ZnAl-LDH (a), FePcS-LDH (b), and FePcS-PMA-LDH (c).

The specific area, pore volume, and pore size of ZnAl-LDH, FePcS-LDH, and FePcS-PMA-LDH were measured by nitrogen adsorption-desorption isotherms. As shown in Figure 5, ZnAl-LDH, FePcS-LDH, and FePcS-PMA-LDH exhibited type H3 hysteresis loops of the Brunauer-DemingDeming-Teller (BDDT) type IV isotherm [40], illustrating the above catalysts belong to the characteristic of mesoporous materials [41,42].

The specific areas, pore volumes, and pore sizes of the three samples are listed in Table 2, where the specific area, pore volume, and pore size of ZnAl-LDH were $9 \mathrm{~m}^{2} / \mathrm{g}, 0.012 \mathrm{~cm}^{3} / \mathrm{g}$, and $16.6 \mathrm{~nm}$, respectively. After loaded with FePcS, the values increased to $16 \mathrm{~m}^{2} / \mathrm{g}, 0.031 \mathrm{~cm}^{3} / \mathrm{g}$, and $18.0 \mathrm{~nm}$, respectively. For FePcS-PMA-LDH, the corresponding values $\left(22 \mathrm{~m}^{2} / \mathrm{g}, 0.041 \mathrm{~cm}^{3} / \mathrm{g}\right.$, and $\left.21.7 \mathrm{~nm}\right)$ were higher than those of ZnAl-LDH and FePcS-LDH, suggesting that FePcS-PMA-LDH can provide more catalytic active sites in the process of pollutant degradation [43]. These results are in agreement with the SEM observations.

Table 2. Brunauer-Emmett-Teller (BET) surface areas, pore volumes, and pore sizes of ZnAl-LDH, FePcS-LDH, and FePcS-PMA-LDH.

\begin{tabular}{cccc}
\hline Samples & BET Surface Area $\left(\mathbf{m}^{\mathbf{2}} \mathbf{g}\right)$ & Pore Volume $\left(\mathbf{c m}^{\mathbf{3}} \mathbf{g}\right)$ & Pore Size $(\mathbf{n m})$ \\
\hline ZnAl-LDH & 9 & 0.012 & 16.6 \\
\hline FePcS-LDH & 16 & 0.031 & 18.0 \\
\hline FePcS-PMA-LDH & 22 & 0.041 & 21.7 \\
\hline
\end{tabular}




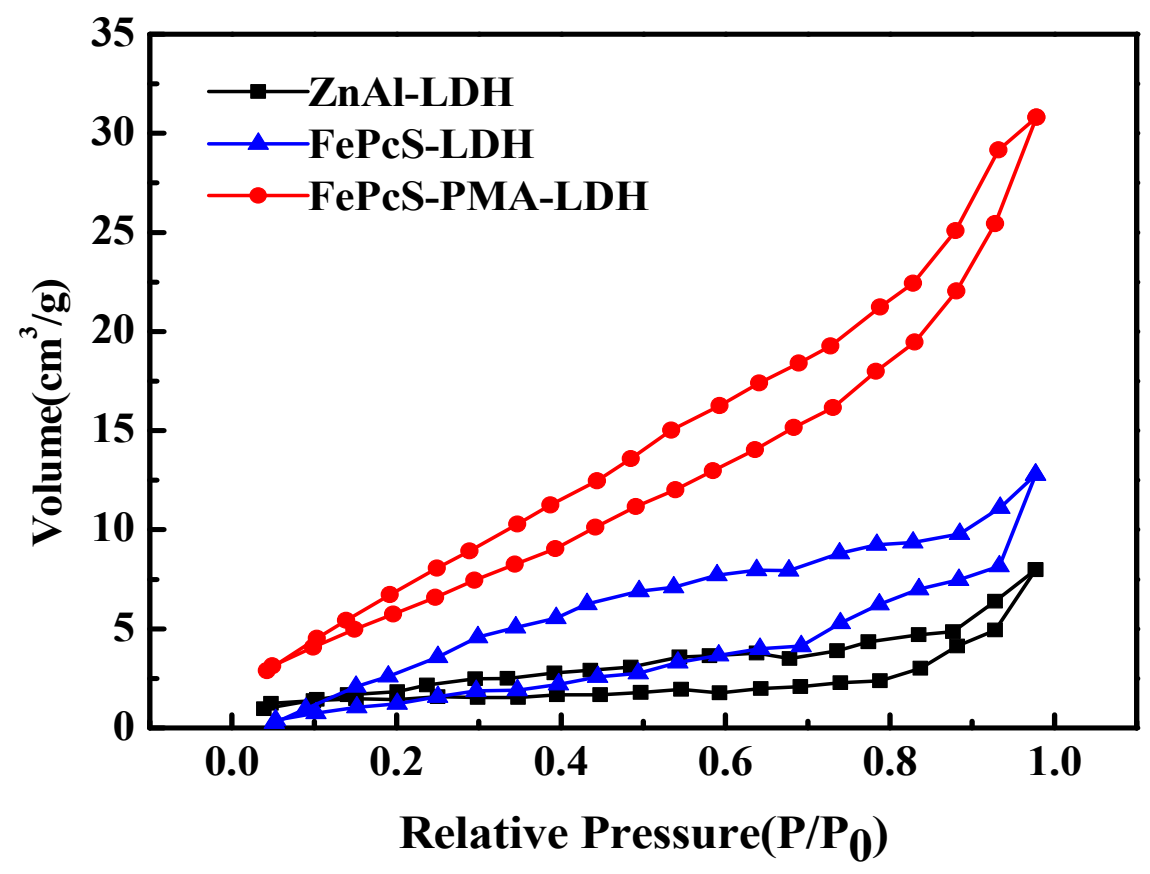

Figure 5. Nitrogen adsorption-desorption isotherms of ZnAl-LDH, FePcS-LDH, and FePcSPMA-LDH.

From the UV-Vis diffused reflectance spectra of ZnAl-LDH, FePcS-LDH, and FePcS-PMA-LDH (Figure 6), it can be seen that FePcS-PMA-LDH had two strong absorption bands at around $650 \mathrm{~nm}$ and $350 \mathrm{~nm}$, while ZnAl-LDH exhibited an absorption only in the ultraviolet light region (250-340 nm). The additional UV-Vis absorbance for FePcS-PMA-LDH can be ascribed to the existence of FePcS with the "Q-band" and "B-band" absorption band [44]. Additionally, because of the existence of PMA, the region of absorption peak around $650 \mathrm{~nm}$ for FePcS-PMA-LDH was larger than that for FePcS-LDH.

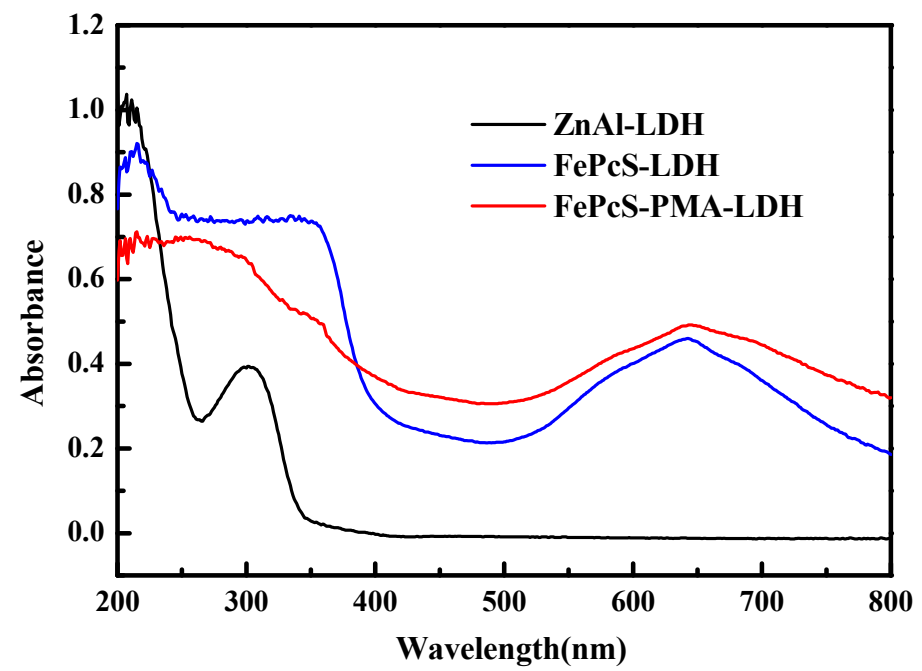

Figure 6. Diffuse reflectance spectra of ZnAl-LDH, FePcS-LDH, and FePcS-PMA-LDH.

\subsection{Catalytic Performance of Samples}

Figure 7 shows the degradation and mineralization of BPA in aqueous solution by various systems, in which the experimental conditions of the photo-Fenton reaction were decided according the influence factor experiments (Figures S1-S4). As shown in Figure 7, negligible degradation and mineralization of BPA in the system with only visible light (curve a) indicates that BPA is quite stable under visible light irradiation. Under the dark conditions (curves b-e), the degradation and 
mineralization rates of BPA are rarely increased, which may be caused by the fact that $\mathrm{H}_{2} \mathrm{O}_{2}$ cannot be converted into $\bullet \mathrm{OH}$ radicals without light irradiation. Additionally, only $28.6 \%$ of BPA was removed in the "Vis/FePcS-PMA-LDH" system (curve f), demonstrating that it is inefficient to degrade BPA when FePcS-PMA-LDH is only used as a photocatalyst. While in the "Vis/ $\mathrm{H}_{2} \mathrm{O}_{2}$ " (curve g) and "Vis $/ \mathrm{H}_{2} \mathrm{O}_{2} / \mathrm{ZnAl}-\mathrm{LDH}$ " (curve h) systems, the degradation efficiencies of BPA were $90.8 \%$ and $91.2 \%$ after only 80 min irradiation (Figure 7a), however, both of them had limited Total Organic Carbon (TOC) removal efficiencies, which were $18.5 \%$ and $18.9 \%$, respectively (Figure $7 \mathrm{~b}$ ). These results indicate that the hydroxyl radicals released in this system can only degrade BPA into longer-lived intermediates. As for the "Vis $/ \mathrm{H}_{2} \mathrm{O}_{2} / \mathrm{FePcS}-\mathrm{LDH}$ " (curve i) and the "Vis/ $\mathrm{H}_{2} \mathrm{O}_{2} / \mathrm{FePcS}-\mathrm{PMA}-\mathrm{LDH}$ " (curve j) systems, the BPA degradation achieved $100 \%$ due to the photo-Fenton like reaction [45-47]. However, the BPA mineralization efficiency in the Vis/ $\mathrm{H}_{2} \mathrm{O}_{2} / \mathrm{FePcS}-\mathrm{PMA}-\mathrm{LDH}$ system (69.2\%) within 180 min was much larger than that in the Vis/ $\mathrm{H}_{2} \mathrm{O}_{2} / \mathrm{FePcS}-\mathrm{LDH}$ system (41.4\%). Moreover, compared with the kinetic rate constants of ZnAl-LDH, FePcS-LDH, and FePcS-PMA-LDH (shown in Figure 8), the kinetic rate constant of FePcS-PMA-LDH $\left(0.061 \mathrm{~min}^{-1}\right)$ was higher than that of ZnAl-LDH $\left(0.022 \mathrm{~min}^{-1}\right)$ and FePcS-LDH $\left(0.032 \mathrm{~min}^{-1}\right)$. These results show that FePcS-PMA-LDH has better catalytic activity than ZnAl-LDH and FePcS-LDH for the degradation of BPA under circumneutral pH condition.
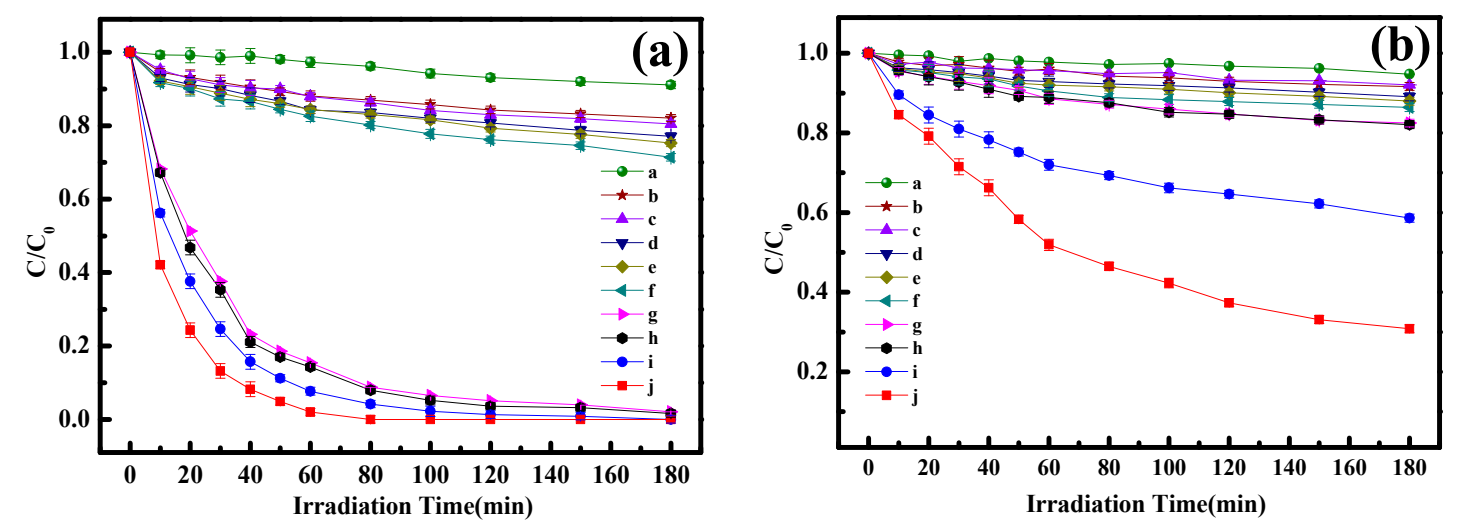

Figure 7. (a) Degradation of bisphenol A (BPA) under different conditions. (b) Mineralization of BPA under different conditions. (a) Vis; (b) $\mathrm{H}_{2} \mathrm{O}_{2}$; (c) $\mathrm{H}_{2} \mathrm{O}_{2} / \mathrm{ZnAl}-\mathrm{LDH}$; (d) $\mathrm{H}_{2} \mathrm{O}_{2} / \mathrm{FePcS}-\mathrm{LDH}$; (e) $\mathrm{H}_{2} \mathrm{O}_{2}$ /FePcS-PMA-LDH; (f) Vis/FePcS-PMA-LDH; (g) Vis/ $\mathrm{H}_{2} \mathrm{O}_{2}$; (h) Vis $/ \mathrm{H}_{2} \mathrm{O}_{2} / \mathrm{ZnAl}-\mathrm{LDH}$; (i) Vis $/ \mathrm{H}_{2} \mathrm{O}_{2} / \mathrm{FePcS}-\mathrm{LDH}$; (j) Vis/ $\mathrm{H}_{2} \mathrm{O}_{2} / \mathrm{FePcS}-\mathrm{PMA}-\mathrm{LDH}$. [BPA] = $10 \mathrm{mg} / \mathrm{L}$; $\left[\mathrm{H}_{2} \mathrm{O}_{2}\right]=6 \mathrm{mM}$; $\mathrm{pH}$ $=6.0 ;$ catalyst dosage $=0.4 \mathrm{~g} / \mathrm{L} ;$ Light intensity $=500 \mathrm{~W}$.

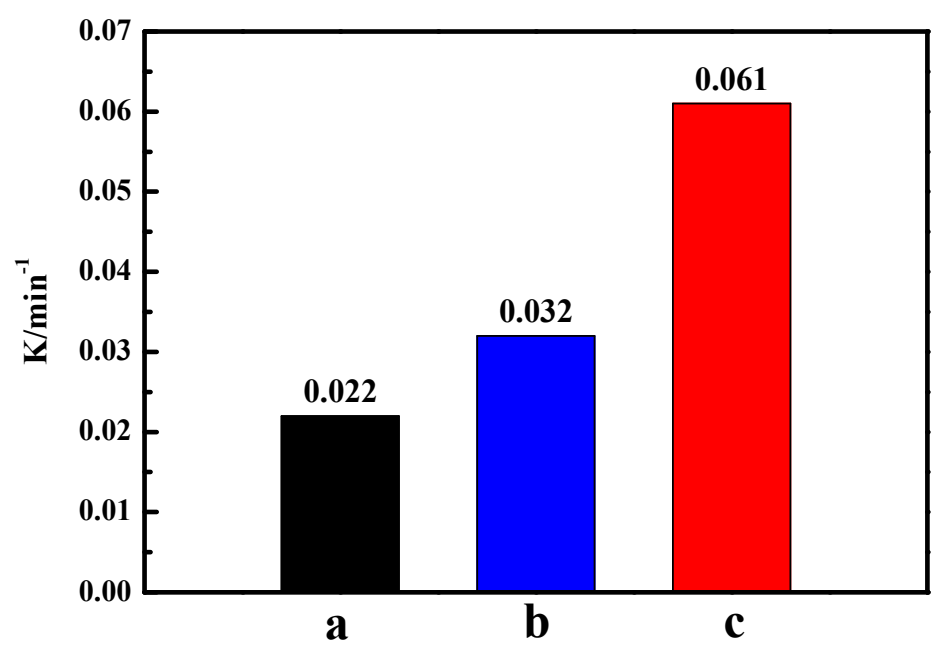

Figure 8. The kinetic rate constant of BPA degradation in the photo-Fenton system with different catalysts. (a-c) represent ZnAl-LDH, FePcS-LDH, and FePcS-PMA-LDH, respectively. 
The stability is also an important index in the practical application of the catalyst. The stability of FePcS-PMA-LDH was evaluated by recycling tests (Figure 9), where the results show that the degradation and mineralization reached $97.6 \%$ and $65.3 \%$ after three cycles, implying that the catalyst is relatively stable in photo-Fenton catalytic applications.

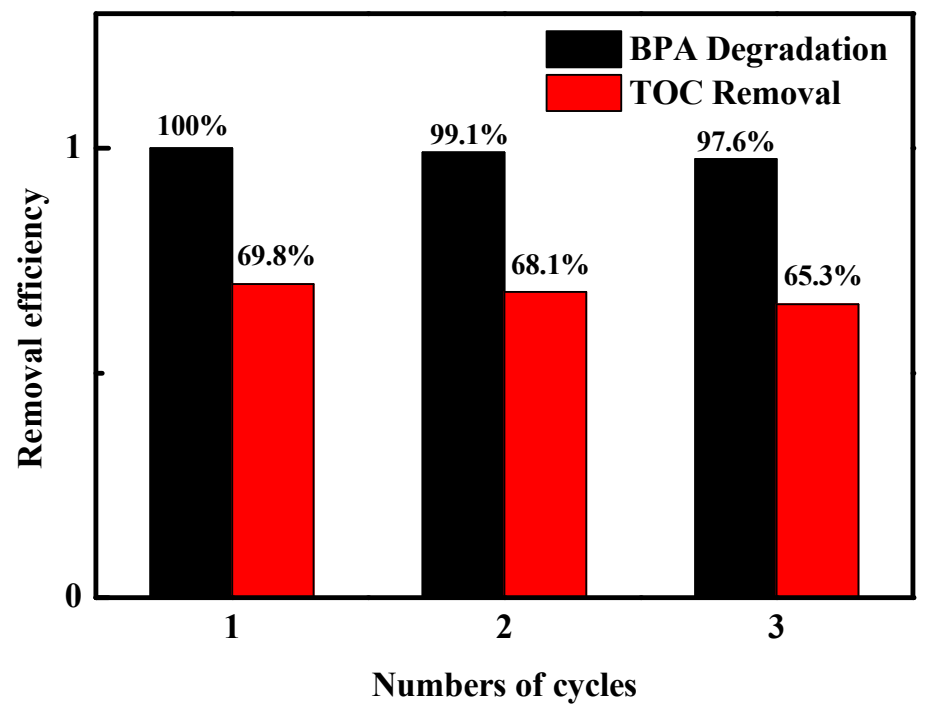

Figure 9. Cycling runs in the heterogeneous photo-Fenton system with FePcS-PMA-LDH.

\subsection{Photo-Fenton Mechanism Discussion}

To explore the catalytic mechanism of the photo-Fenton system with FePcS-PMA-LDH, active species capture experiments were carried out. In these experiments, isopropanol (IPA), p-benzoquinone (PBQ), ammonium oxalate $(\mathrm{AO})$, and sodium azide $\left(\mathrm{NaN}_{3}\right)$ were applied as the scavengers of $\bullet \mathrm{OH}$, $\mathrm{O}_{2}{ }^{\bullet-}, \mathrm{h}^{+}$and ${ }^{1} \mathrm{O}_{2}$, respectively. The results of the experiments are shown in Figure 10, it can be clearly seen that the degradation of BPA is more or less suppressed by these four scavengers. Particularly, the suppression of BPA degradation by IPA, PBQ, and $\mathrm{NaN}_{3}$ were more prominent than that by $\mathrm{AO}$, which means that $\bullet \mathrm{OH}, \mathrm{O}_{2}{ }^{\bullet-}$ and ${ }^{1} \mathrm{O}_{2}$ play main roles in the system.
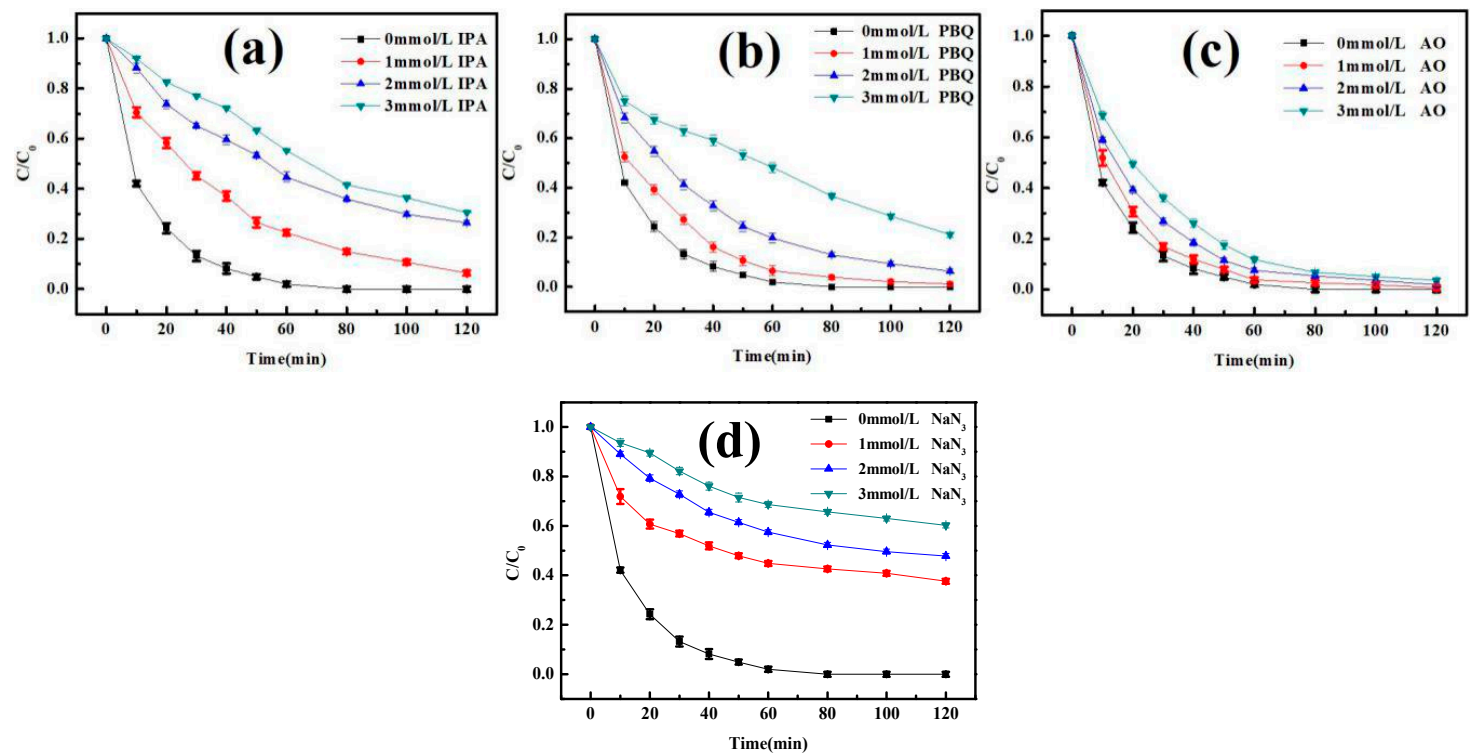

Figure 10. Effects of (a) isopropanol, (b) p-benzoquinone, (c) ammonium oxalate (AO), and (d) sodium azide $\left(\mathrm{NaN}_{3}\right)$ on the degradation of BPA in the heterogeneous photo-Fenton system with FePcS-PMA-LDH. 
In order to understand the production path of hydroxyl radicals, superoxide radicals, and singlet oxygen, the corresponding ESR spin trapping experiments were carried out in the systems with ZnAl-LDH, PMA-LDH, FePcS-LDH, and FePcS-PMA-LDH, respectively. As shown in Figure 11, significant signals of $\bullet \mathrm{OH}, \mathrm{O}_{2}{ }^{\bullet}$, and ${ }^{1} \mathrm{O}_{2}$ can be detected in the systems with FePcS-LDH and FePcS-PMA-LDH, which were much stronger than that in the PAM-LDH and ZnAl-LDH systems. These results demonstrate that the generation of these radicals is mainly due to the existence of FePcS. As a kind of Fe complexes, FePcS was extensively studied as a photo-Fenton catalyst, in which the iron center can react with $\mathrm{H}_{2} \mathrm{O}_{2}$ to form $\bullet \mathrm{OH}[47,48]$. In addition, $\mathrm{FePcS}$ proved that it could be excited to generate an excited state $\left(\mathrm{FePcS}^{*}\right)$ upon irradiation, which can interact with $\mathrm{O}_{2}$ to form $\mathrm{O}_{2}{ }^{\bullet-}$ and ${ }^{1} \mathrm{O}_{2}$ [48]. Compared with the FePcS-LDH system, the signals of $\bullet \mathrm{OH}, \mathrm{O}_{2}{ }^{\bullet-}$, and ${ }^{1} \mathrm{O}_{2}$ were all further enhanced in the FePcS-PMA-LDH system, which verified that the addition of PMA is favorable to the formation of these active species. According to the study of Chen et al. [18], polyoxometalates (POM) can easily capture electrons from electron acceptors to form reduced $\mathrm{POM}\left(\mathrm{POM}^{-}\right)$. $\mathrm{POM}^{-}$can not only promote the transition between $\mathrm{Fe}(\mathrm{III})$ to $\mathrm{Fe}(\mathrm{II})$ in FePc to accelerate the Fenton-like reaction, but can also directly reduce $\mathrm{O}_{2}$ to $\mathrm{O}_{2}{ }^{\bullet-}$. Therefore, as a kind of POM, PMA has a synergistic effect with $\mathrm{FePcS}$ in the generation of $\bullet \mathrm{OH}, \mathrm{O}_{2}{ }^{\bullet-}$, and ${ }^{1} \mathrm{O}_{2}$.
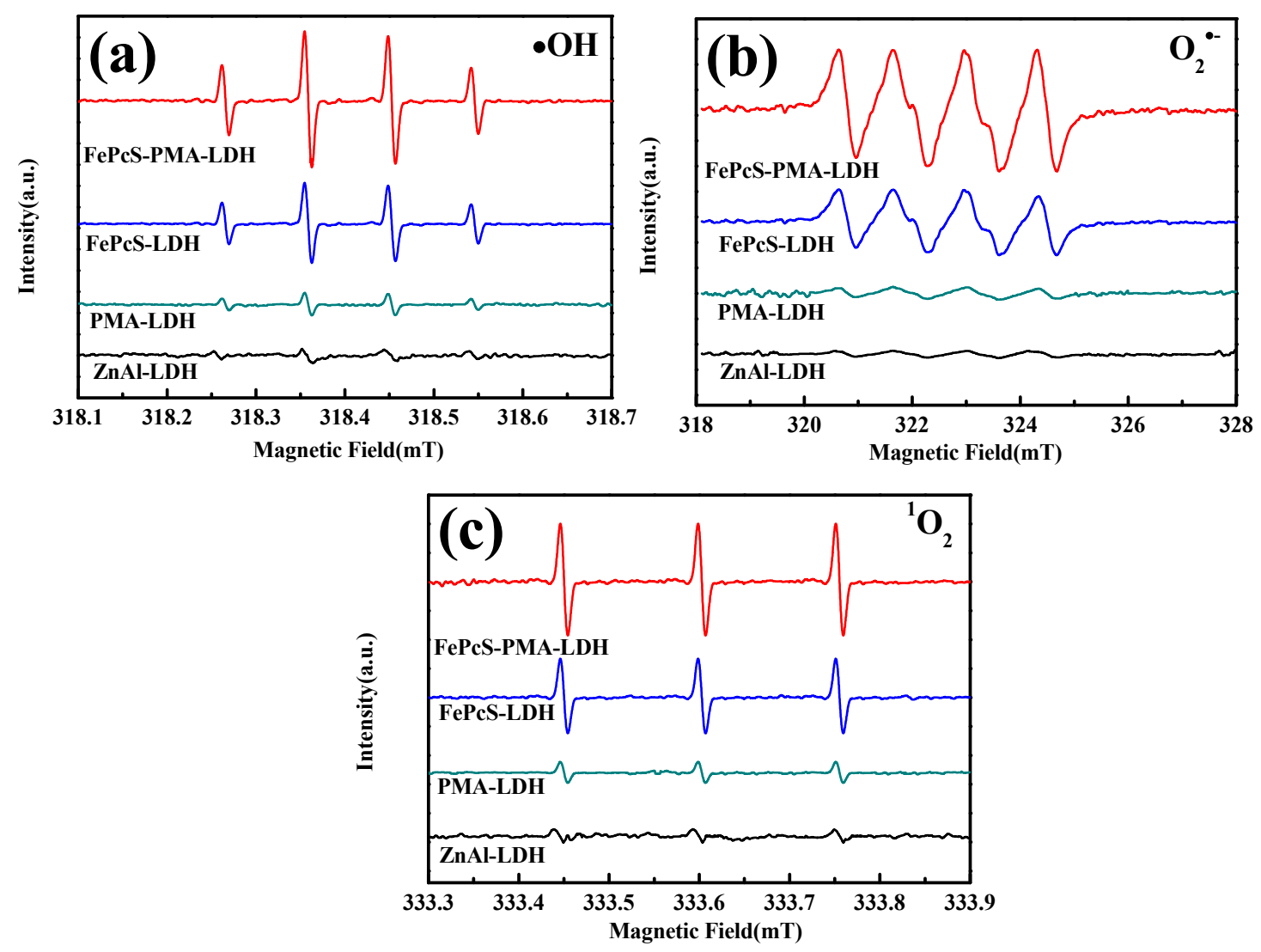

Figure 11. Electron spin resonance (ESR) spectra of (a) DMPO-HO- adducts, (b) DMPO- ${ }_{2}{ }^{\bullet-}$ adducts and (c) TEMP- ${ }^{1} \mathrm{O}_{2}$ adducts in the photo-Fenton system with $\mathrm{ZnAl}-\mathrm{LDH}, \mathrm{PMA}-\mathrm{LDH}$, FePcS-LDH, and FePcS-PMA-LDH under visible light irradiation.

The electrochemical measurements were carried out to investigate the process of electron transfer. The CV curves of ZnAl-LDH/GCE, FePcS-LDH/GCE, and FePcS-PMA-LDH/GCE are shown in Figure 12. The CV curves of ZnAl-LDH/GCE and FePcS-LDH/GCE show a couple of small redox peaks, whereas the FePcS-PMA-LDH modified GCE shows a pair of stable, symmetrical, and obvious redox peaks. These results imply that a faster electron transfer occurred on the surface of the 
FePcS-PMA-LDH/GCE electrode [49-51], which promotes the redox reaction between Fe(III) to Fe(II) in the iron center of FePcS.

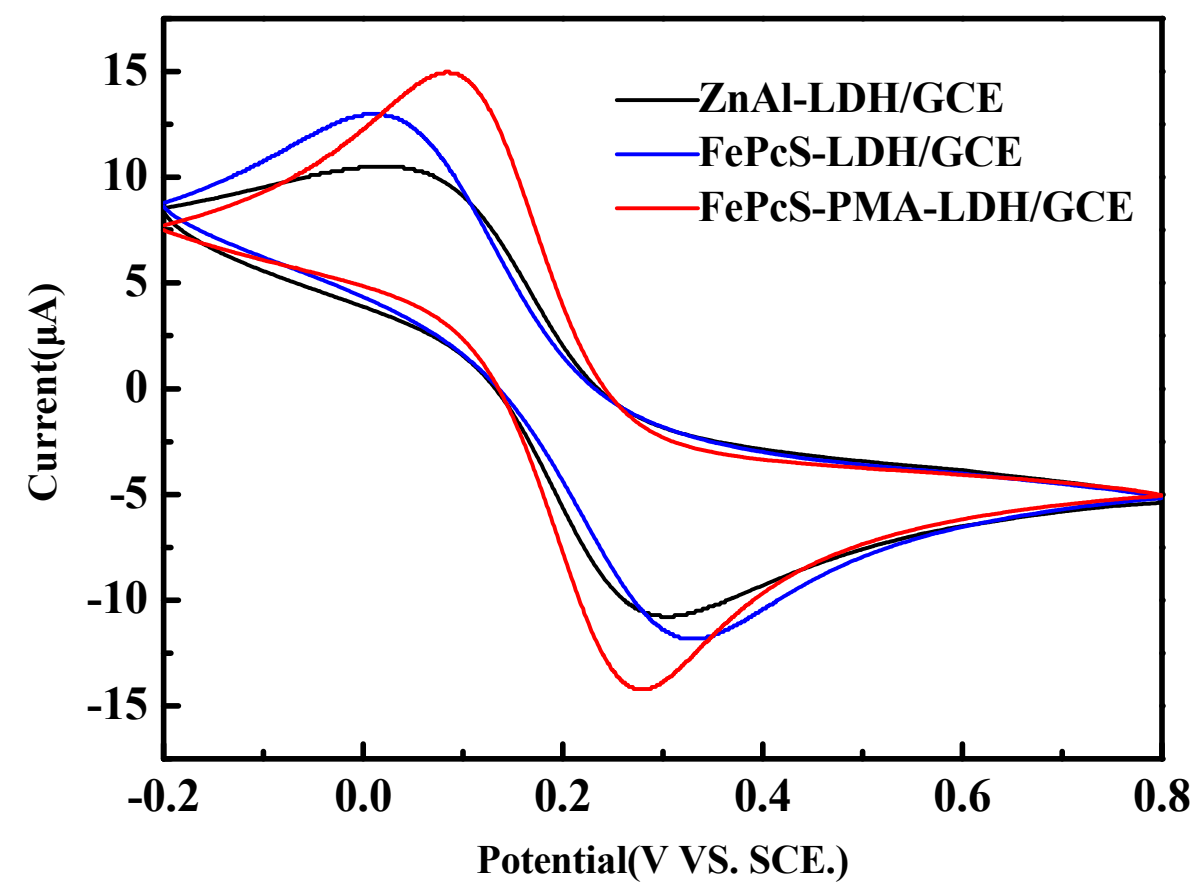

Figure 12. Cyclic voltammetry of ZnAl-LDH/GCE, FePcS-LDH/GCE, and FePcS-PMA-LDH/GCE in $0.1 \mathrm{M} \mathrm{KCl}$ solution containing $\mathrm{K}_{3}\left[\mathrm{Fe}(\mathrm{CN})_{6}\right] / \mathrm{K}_{4}\left[\mathrm{Fe}(\mathrm{CN})_{6}\right]$ (both $5 \mathrm{mM}$ ) with a scan rate of $10 \mathrm{mV} / \mathrm{s}$.

The above results can also be confirmed by the EIS measurements. According to previous reports [52-55], the smaller radius of the Nyquist circle implies a faster electron transfer rate. As shown in Figure 13, the radius on the EIS Nyquist plot of FePcS-PMA-LDH/GCE was much smaller than that of ZnAl-LDH/GCE and FePcS-LDH/GCE, indicating a faster charge transfer occurred on the interface of the FePcS-PMA-LDH/GCE electrode. These results show that the presence of FePcS and PMA make the electron transfer easier and thus favor the photo-Fenton treatment in water.

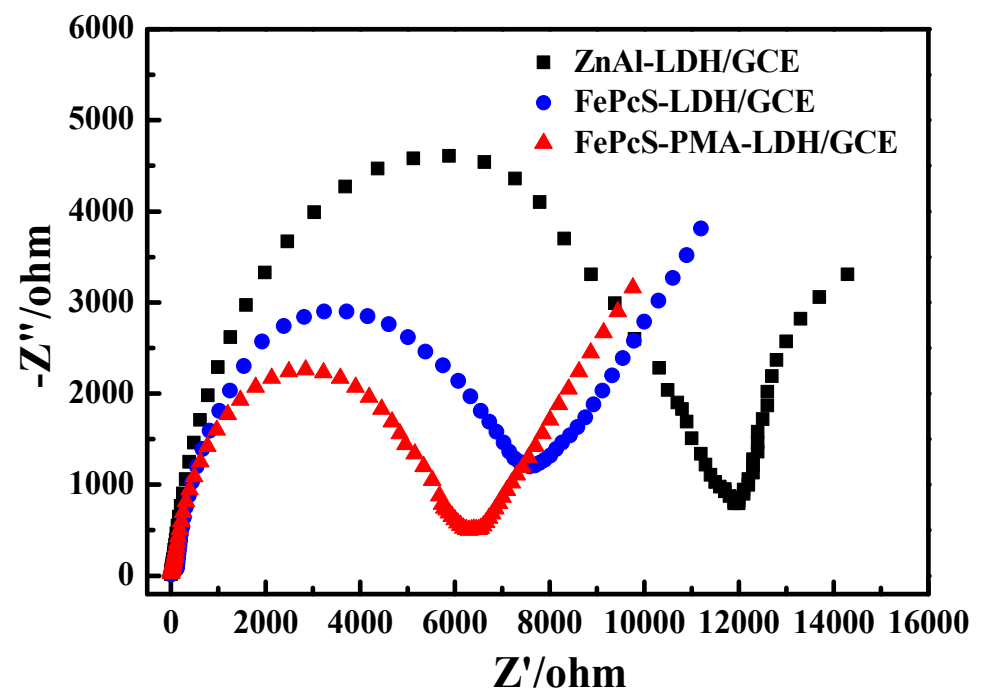

Figure 13. Nyquist diagrams obtained at ZnAl-LDH/GCE, FePcS-LDH/GCE, and FePcS-PMA-LDH/ GCE in $0.1 \mathrm{M} \mathrm{KCl}$ solution containing $\mathrm{K}_{3}\left[\mathrm{Fe}(\mathrm{CN})_{6}\right] / \mathrm{K}_{4}\left[\mathrm{Fe}(\mathrm{CN})_{6}\right]$ (both $5 \mathrm{mM}$ ). 
According to the above experiments, the main contribution of PMA to the enhanced photo-Fenton activity of FePcS-PMA-LDH comes from the acceleration of electron transfer in the reaction system. The possible reaction mechanism can be proposed in Figure 14. FePcS can first be excited under the irradiation of visible light. Then, PMA can capture electrons from the excited FePcS to generate reduced PMA (PMA ${ }^{-}$). On one hand, $\mathrm{PMA}^{-}$can reduce $\mathrm{Fe}(\mathrm{III})-\mathrm{PcS}$ to $\mathrm{Fe}(\mathrm{II})-\mathrm{PcS}$, which can react with $\mathrm{H}_{2} \mathrm{O}_{2}$ to form $\bullet \mathrm{OH}$. On the other hand, $\mathrm{PMA}^{-}$can directly act with $\mathrm{O}_{2}$, leading to the formation of $\mathrm{O}_{2}{ }^{\bullet-}$. Furthermore, $\mathrm{O}_{2}$ can directly react with excited FePcS to form $\mathrm{O}_{2}{ }^{\bullet-}$, and ${ }^{1} \mathrm{O}_{2}$. Therefore, $\bullet \mathrm{OH}_{1} \mathrm{O}_{2}{ }^{\bullet-}$, and ${ }^{1} \mathrm{O}_{2}$ become the main active species for BPA degradation in this system. Of course, the roles of PMA in the studied catalyst need to be further investigated.

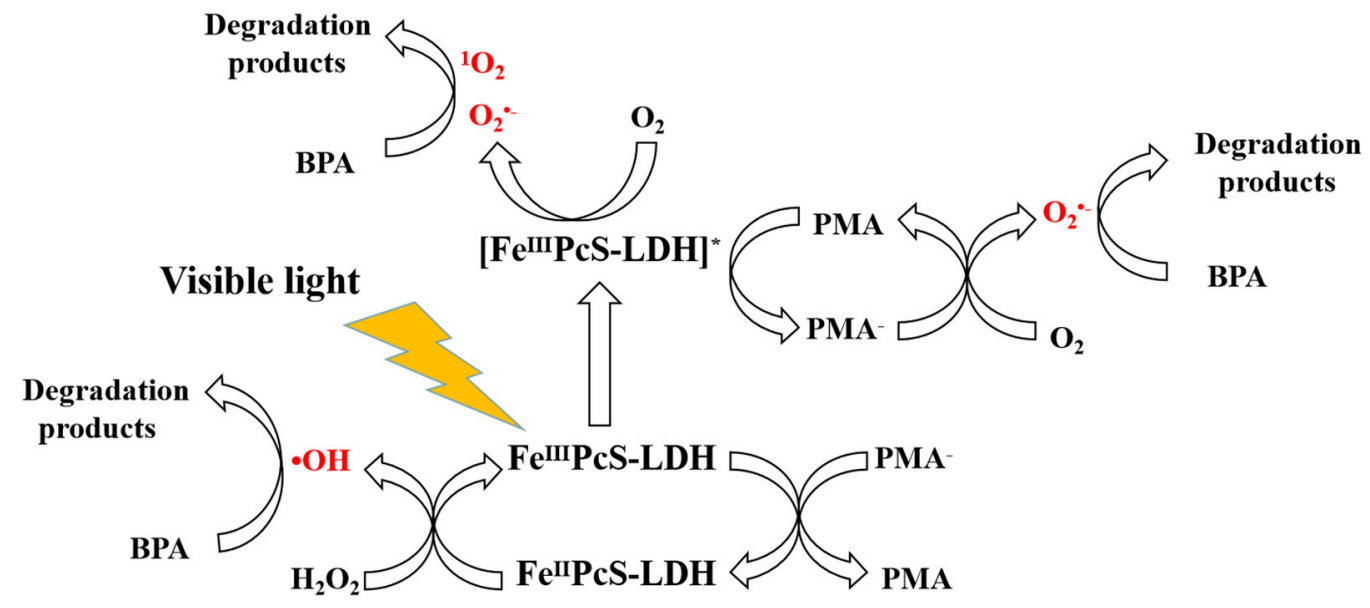

Figure 14. The possible photo-Fenton catalytic mechanism of FePcS-PMA-LDH to degrade BPA.

\section{Conclusions}

A FePcS-PMA-LDH composite was successfully synthesized by the anion exchange method. The photo-Fenton catalytic activity of the as-prepared FePcS-PMA-LDH composite in the degradation of PBA was investigated under visible-light irradiation and circumneutral $\mathrm{pH}$. The results showed that the FePcS-PMA-LDH composite exhibited superior catalytic activity and excellent stability. In addition, the possible photo-Fenton catalytic mechanism of FePcS-PMA-LDH was also proposed.

Supplementary Materials: The following are available online at http://www.mdpi.com/1996-1944/13/8/1951/s1, Figure S1: Effects of initial $\mathrm{pH}$ value on the degradation of BPA. ([BPA] $=10 \mathrm{mg} / \mathrm{L} ;\left[\mathrm{H}_{2} \mathrm{O}_{2}\right]=6 \mathrm{mM}$; catalyst dosage $=0.4 \mathrm{~g} / \mathrm{L}$; Light intensity $=500 \mathrm{~W}$.), Figure S2: Effects of $\mathrm{H}_{2} \mathrm{O}_{2}$ dosages on the degradation of BPA. $([\mathrm{BPA}]=10 \mathrm{mg} / \mathrm{L} ; \mathrm{pH}=6.0$; catalyst dosage $=0.4 \mathrm{~g} / \mathrm{L} ;$ Light intensity $=500 \mathrm{~W}$.), Figure S3: Effects of light intensity on the degradation of BPA. ([BPA] $=10 \mathrm{mg} / \mathrm{L} ;\left[\mathrm{H}_{2} \mathrm{O}_{2}\right]=6 \mathrm{mM} ; \mathrm{pH}=6.0$; catalyst dosage $=0.4 \mathrm{~g} / \mathrm{L}$.), Figure S4: Effects of catalyst loading on the degradation of BPA. ([BPA] $=10 \mathrm{mg} / \mathrm{L} ;\left[\mathrm{H}_{2} \mathrm{O}_{2}\right]=6 \mathrm{mM} ; \mathrm{pH}=6.0$; Light intensity $=500 \mathrm{~W})$.

Author Contributions: Conceptualization, Y.Q (Yaqun Qiu) and F.H.; Investigation, S.T. and Y.Q. (Yan Qi); Project administration, Y.Q. (Yan Qi), E.L., and L.Z.; Writing—original draft, Y.Q. (Yaqun Qiu) and F.H.; Writing一review and editing, L.Z. and E.L. All authors have read and agreed to the published version of the manuscript.

Funding: This research received no external funding.

Conflicts of Interest: The authors declare no conflict of interest.

\section{References}

1. Huang, W.; Brigante, M.; Wu, F.; Mousty, C.; Hanna, K.; Mailhot, G. Assessment of the Fe(III)-EDDS Complex in Fenton-Like Processes: From the Radical Formation to the Degradation of Bisphenol A. Environ. Sci. Technol. 2013, 47, 1952-1959. [CrossRef]

2. Ortega-Gómez, E.; Martín, M.; Carratalà, A.; Ibañez, P.; Pérez, J.; Pulgarín, C. Principal parameters affecting virus inactivation by the solar photo-Fenton process at neutral $\mathrm{pH}$ and $\mu \mathrm{M}$ concentrations of $\mathrm{H}_{2} \mathrm{O}_{2}$ and $\mathrm{Fe}^{2+} / \mathrm{Fe}^{3+}$. Appl. Catal. B Environ. 2015, 174, 395-402. [CrossRef] 
3. Chen, L.; Ma, J.; Li, X.; Zhang, J.; Fang, J.; Guan, Y. Strong enhancement on fenton oxidation by addition of hydroxylamine to accelerate the ferric and ferrous iron cycles. Environ. Sci. Technol. 2011, 45, 3925-3930. [CrossRef] [PubMed]

4. Monteagudo, J.; Durán, A.; Aguirre, M.; San, M. Optimization of the mineralization of a mixture of phenolic pollutants under a ferrioxalate-induced solar photo-Fenton process. J. Hazard. Mater. 2011, 185, 131-139. [CrossRef] [PubMed]

5. Huang, W.; Brigante, M.; Wu, F.; Hanna, K.; Mailhot, G. Development of a new homogenous photo-Fenton process using Fe(III)-EDDS complexes. J. Photochem. Photobiol. A Chem. 2012, 239, 17-23. [CrossRef]

6. Huang, Z.; Wu, P.; Zhang, X.; Wang, X.; Zhu, N.; Wu, J. Intercalation of Fe(III) complexes into layered double hydroxides: Synthesis and structural preservation. Appl. Clay Sci. 2012, 65, 87-94. [CrossRef]

7. Silva, M.; Calvete, M.; Goncalves, N.; Burrows, H.; Sarakha, M.; Fernandes, A. Zinc(II) phthalocyanines immobilized in mesoporous silica Al-MCM-41 and their applications in photocatalytic degradation of pesticides. J. Hazard. Mater. 2012, 233, 79-88. [CrossRef]

8. Sorokin, A. Phthalocyanine metal complexes in catalysis. Chem. Rev. 2013, 113, 8152-8191. [CrossRef]

9. Granados-Oliveros, G.; Páez-Mozo, E.; Ortega, F.; Ferronato, C.; Chovelon, J.-M. Degradation of atrazine using metalloporphyrins supported on $\mathrm{TiO}_{2}$ under visible light irradiation. Appl. Catal. B Environ. 2009, 89, 448-454. [CrossRef]

10. Kim, W.; Park, J.; Jo, H.; Kim, H.; Choi, W. Visible Light Photocatalysts Based on Homogeneous and Heterogenized Tin Porphyrins. J. Phys. Chem. 2008, 112, 491-499. [CrossRef]

11. Shen, C.; Song, S.; Zang, L.; Kang, X.; Wen, Y.; Liu, W. Efficient removal of dyes in water using chitosan microsphere supported cobalt (II) tetrasulfophthalocyanine with $\mathrm{H}_{2} \mathrm{O}_{2}$. J. Hazard. Mater. 2010, 177, 560-566. [CrossRef] [PubMed]

12. Ozoemena, K.; Kuznetsova, N.; Nyokong, T. Comparative photosensitised transformation of polychlorophenols with different sulphonated metallophthalocyanine complexes in aqueous medium. J. Mol. Catal. A Chem. 2001, 176, 29-40. [CrossRef]

13. Spiller, W.; Kliesch, H.; Hackbarth, S. Singlet Oxygen Quantum Yields of Different Photosensitizers in Polar Solvents and Micellar Solutions. J. Porphyr. Phthalocyanines 1998, 2, 145-158. [CrossRef]

14. Lei, P.; Chen, C.; Yang, J.; Wan, M.; Zhao, J.; Zang, L. Degradation of dye pollutants by immobilized polyoxometalate with $\mathrm{H}_{2} \mathrm{O}_{2}$ under visible-light irradiation. Environ. Sci. Technol. 2005, 39, 8466-8474. [CrossRef] [PubMed]

15. Tachikawa, T.; Fujitsuka, M.; Majima, T. Mechanistic insight into the $\mathrm{TiO}_{2}$ photocatalytic reactions: Design of new photocatalysts. J. Phys. Chem. C 2007, 111, 5259-5275. [CrossRef]

16. Yoon, M.; Chang, J.A.; Kim, Y.; Choi, J.R. Heteropoly Acid-Incorporated $\mathrm{TiO}_{2}$ Colloids as Novel Photocatalytic Systems Resembling the Photosynthetic Reaction Center. J. Phys. Chem. B 2001, 105, 2539-2545. [CrossRef]

17. Ozer, R.; Ferry, J. Investigation of the Photocatalytic Activity of $\mathrm{TiO}_{2}$-Polyoxometalate Systems. Environ. Sci. Technol. 2001, 35, 3242-3246. [CrossRef]

18. Chen, C.C.; Lei, P.X.; Ji, H.W.; Ma, W.H.; Zhao, J.C. Photocatalysis by Titanium Dioxide and Polyoxometalate/ $/ \mathrm{TiO}_{2}$ Cocatalysts. Intermediates and Mechanistic Study. Environ. Sci. Technol. 2004, 38, 329-337. [CrossRef]

19. Kholdeevaa, O.A.; Zalomaeva, O.V. Recent advances in transition-metal-catalyzed selective oxidation of substituted phenols and methoxyarenes with environmentally benign oxidants. Coord. Chem. Rev. 2016, 306, 302-330. [CrossRef]

20. Demel, J.; Lang, K. Layered Hydroxide-Porphyrin Hybrid Materials: Synthesis, Structure, and Properties. Eur. J. Inorg. Chem. 2012, 2012, 5154-5164. [CrossRef]

21. Valente, J.; Tzompantzi, F.; Prince, J. Highly efficient photocatalytic elimination of phenol and chlorinated phenols by $\mathrm{CeO}_{2} / \mathrm{MgAl}$ layered double hydroxides. Appl. Catal. B Environ. 2011, 102, 276-285. [CrossRef]

22. Ahmed, S.; Rasul, M.; Martens, W.; Brown, R.; Hashib, M. Advances in heterogeneous photocatalytic degradation of phenols and dyes in wastewater: A review. Water Air Soil Pollut. 2011, 215, 3-29. [CrossRef]

23. Abellán, G.; Busolo, F.; Coronado, E.; Martígastaldo, C.; Ribera, A. Hybrid Magnetic Multilayers by Intercalation of $\mathrm{Cu}(\mathrm{II})$ Phthalocyanine in LDH Hosts. J. Phys. Chem. C 2012, 116, 15756-15764. [CrossRef]

24. Bourzami, R.; Eyele-Mezui, S.; Delahaye, E.; Drillon, M.; Rabu, P.; Parizel, N. New metal phthalocyanines/metal simple hydroxide multilayers: Experimental evidence of dipolar field-driven magnetic behavior. Inorg. Chem. 2014, 53, 1184-1194. [CrossRef] [PubMed] 
25. Griffin, J.; Bedell, S.; Worley, C. Tetra-Sulfo Iron-Phthalocyanine and Related Methods. U.S. Patent Application No. 8,318,005, 27 November 2012.

26. Bderrazek, A.; Najoua, F.S.; Srasra, E. Synthesis and characterization of [Zn-Al] LDH:Study of the effect of calcination on the photocatalytic activity. Appl. Clay Sci. 2016, 119, 229-235. [CrossRef]

27. Hadnadjev-Kostic, M.; Vulic, T.; Marinkovic-Neducin, R. Photo-induced properties of photocatalysts: A study on the modified structural, optical and textural properties of $\mathrm{TiO}_{2}-\mathrm{ZnAl}$ layered double hydroxide based materials. J. Clean. Prod. 2017, 164,1-18. [CrossRef]

28. Li, X.H.; Yu, Z.X.; Shao, L.Y.; Zeng, H.J.; Liu, Y.C.; Feng, X.F. A novel strategy to construct a visible-light-driven Z-scheme ( $\mathrm{ZnAl}-\mathrm{LDH}$ with active phase/g- $\mathrm{C}_{3} \mathrm{~N}_{4}$ ) heterojunction catalyst via polydopamine bridge (a similar "bridge" structure). J. Hazard. Mater. 2020, 386, 121650. [CrossRef]

29. Isupov, V.P.; Chupakhina, L.E.; Mitrofanova, R.P. Synthesis and thermolysis of lithium aluminum double hydroxide containing [Fe(OH)EDTA ${ }^{2-}$ ]. Russ. J. Inorg. Chem. 2009, 54, 204-210. [CrossRef]

30. Suárez-Quezada, M.; Mantilla, A. $\mathrm{H}_{2}$ production by the water splitting reaction using photocatalysts derived from calcined ZnAl-LDH. Fuel 2019, 240, 262-269. [CrossRef]

31. Liu, L.L.; Cheng, M.; Yang, Z.H. Improved performance of flower-like ZnAl-LDH growing on carbon nanotubes used in zincenickel secondary battery. Electrochim. Acta 2018, 227, 67-76.

32. Xing, R.; Liu, N.; Liu, Y.; Wu, H.; Jiang, Y.; Chen, L. Novel Solid Acid Catalysts: Sulfonic Acid Group-Functionalized Mesostructured Polymers. Adv. Funct. Mater. 2007, 17, 2455-2461. [CrossRef]

33. Liu, X.B.; Chang, F.X.; Xu, L.; Yang, Y.Z.; Liu, M. Preparation of ordered carbon/silica hybrid mesoporous materials with specific pore size expansion. Microporous Mesoporous Mater. 2005, 79, 269-273. [CrossRef]

34. González, L.; Villa de, P.A.; Montes, D.; Sorokin, A. Allylic oxidation of cyclohexene over silica immobilized iron tetrasulfophthalocyanine. Tetrahedron Lett. 2006, 47, 6465-6468. [CrossRef]

35. Li, T.T.; Liu, C.; Zhang, Z.; Li, B.A.; Yang, C. Preparation and Performance of POMs/PS/PVA Electrospinning Fiber Membranes. Chem. J. Chin. Univ. 2014, 35, 389-395.

36. Sampurnam, S.; Dhanasekaran, T.; Narayanan, V. Synthesis, Characterization, and Photocatalytic activity of Silver nanoparticledoped Phosphomolybdic acid supportedZirconia. Mater. Today Proc. 2019, 14, 558-562. [CrossRef]

37. Armatas, G.S.; Bilis, G.; Louloudi, M. Highly ordered mesoporous zirconia-polyoxometalate nanocomposite materials for catalytic oxidation of alkenes. J. Mater. Chem. 2011, 21, 2997-3005. [CrossRef]

38. Xu, Z.P.; Jin, Y.; Liu, S.; Hao, Z.P.; Lu, G.Q. Surface charging of layered double hydroxides during dynamic interactions of anions at the interfaces. J. Colloid Interface Sci. 2008, 326, 522-529. [CrossRef] [PubMed]

39. Li, D.; Xu, X.; Xu, J.; Hou, W. Poly(ethylene glycol) haired layered double hydroxides as biocompatible nanovehicles: Morphology and dispersity study. Colloids Surf. A Physicochem. Eng. Asp. 2011, 384, 585-591. [CrossRef]

40. Sangwichien, C.; Aranovich, G.L.; Donohue, M.D. Density functional theory predictions of adsorption isotherms with hysteresis loops. Colloids Surf. A Physicochem. Eng. Asp. 2002, 206, 313-320. [CrossRef]

41. Gong, Q.J.; Liu, Y.; Dang, Z. Core-shell structured $\mathrm{Fe}_{3} \mathrm{O}_{4} @ G O @ M I L-100(\mathrm{Fe})$ magnetic nanoparticles as heterogeneous photo-Fenton catalyst for 2,4-dichlorophenol degradation under visible light. J. Hazard. Mater. 2019, 371, 677-686. [CrossRef]

42. Xu, T.; Liu, Y.; Ge, F.; Ouyang, Y. Simulated solar light photooxidation of azocarmine B over hydroxyl iron-aluminum pillared bentonite using hydrogen peroxide. Appl. Clay Sci. 2014, 100, 35-42. [CrossRef]

43. Jiang, L.B.; Yuan, X.Z.; Zeng, G.M.; Liang, J. In-situ synthesis of direct solid-state dual Z-scheme $\mathrm{WO}_{3} / \mathrm{g}-\mathrm{C}_{3} \mathrm{~N}_{4} / \mathrm{Bi}_{2} \mathrm{O}_{3}$ photocatalyst for the degradation of refractory pollutant. Appl. Catal. B Environ. 2018, 227, 376-385. [CrossRef]

44. Leznoff, C.; Lever, A. Phthalocyanines. Properties and applications; Weinheim/VCH Publishers: New York, NY, USA, 1989; pp. 99-117.

45. Stepanow, S.; Rizzini, A.L.; Krull, C.; Kavich, J.; Cezar, J.C.; Harris, F.Y.; Sheverdyaeva, P.M.; Moras, P.; Carbone, C.; Ceballos, G.; et al. Spin tuning of electron-doped metal-phthalocyanine Layers. J. Am. Chem. Soc. 2014, 136, 5451-5459. [CrossRef] [PubMed]

46. Ponce, I.; Silva, J.F.; Onate, R.; Rezende, M.C.; Paez, M.A.; Zagal, J.H.; Pavez, J. Enhancement of the catalytic activity of Fe phthalocyanine for the reduction of $\mathrm{O}_{2}$ anchored to $\mathrm{Au}(111)$ via conjugated self-assembled monolayers of aromatic thiols as compared to $\mathrm{Cu}$ phthalocyanine. J. Phys. Chem. C 2012, 116, 15329-15341. [CrossRef] 
47. Zhu, Z.X.; Chen, Y.; Gu, Y.; Wu, F.; Lu, W.Y.; Xu, T.F.; Chen, W.X. Catalytic degradation of recalcitrant pollutants by Fenton-like process using polyacrylonitrile-supported iron(II) phthalocyanine nanofibers: Intermediates and pathway. Water Res. 2016, 93, 296-305. [CrossRef] [PubMed]

48. Tang, X.X.; Liu, Y. Heterogeneous photo-Fenton degradation of methylene blue under visible irradiation by iron tetrasulphophthalocyanine immobilized layered double hydroxide at circumneutral pH. Dye Pigment 2016, 134, 397-408. [CrossRef]

49. Zhu, W.; Zhang, W.; Li, S.; Ma, H.; Chen, W.; Pang, H. Fabrication and electrochemical sensing performance of a composite film containing a phosphovanadomolybdate and cobalt(II) tetrasulfonate phthalocyanine. Sens. Actuators B Chem. 2013, 181, 773-781. [CrossRef]

50. Agboola, B.; Pillay, J.; Makgopa, K.; Ozoemena, K. Electrochemical Characterization of Mixed Self-Assembled Films of Water-Soluble Single-Walled Carbon Nanotube-Poly (m-aminobenzene sulfonic acid) and Iron (II). J. Electrochem. Soc. 2010, 157, F159-F166. [CrossRef]

51. Li, N.; Zhu, M.; Qu, M.; Gao, X.; Li, X.; Zhang, W. Iron-tetrasulfophthalocyanine functionalized graphene nanosheets: Attractive hybrid nanomaterials for electrocatalysis and electroanalysis. J. Electroanal. Chem. 2011, 651, 12-18. [CrossRef]

52. Xia, J.; Ge, Y.; Di, J.; Xu, L.; Yin, S.; Chen, Z.; Liu, P.; Li, H. Ionic liquid-assisted strategy for bismuth-rich bismuth oxybromides nanosheets with superior visible light-driven photocatalytic removal of bisphenol-A. J. Colloid Interface Sci. 2016, 473, 112-119. [CrossRef]

53. Xu, Y.; Huang, S.; Xie, M.; Li, Y.; Jing, L.; Xu, H. Core-shell magnetic Ag/AgCl@ $\mathrm{Fe}_{2} \mathrm{O}_{3}$ photocatalysts with enhanced photoactivity for eliminating bisphenol A and microbial contamination. New J. Chem. 2016, 40, 3413-3422. [CrossRef]

54. Di, J.; Xia, J.; Yin, S.; Xu, H.; Xu, L.; Xu, Y. Preparation of sphere-like g- $\mathrm{C}_{3} \mathrm{~N}_{4} / \mathrm{BiOI}$ photocatalysts via a reactable ionic liquid for visible-light-driven photocatalytic degradation of pollutants. J. Mater. Chem. A 2014, 2, 5340-5351. [CrossRef]

55. Zhou, M.; Wu, H.B.; Bao, J.; Xie, Y. Ordered macroporous $\mathrm{BiVO}_{4}$ architectures with controllable dual porosity for efficient solar water splitting. Angew. Chem. 2013, 52, 8741-8745. [CrossRef]

(C) 2020 by the authors. Licensee MDPI, Basel, Switzerland. This article is an open access article distributed under the terms and conditions of the Creative Commons Attribution (CC BY) license (http://creativecommons.org/licenses/by/4.0/). 